Journal of Materials and Environmental Sciences ISSN : 2028-2508

CODEN : JMESCN

Copyright $\odot 2017$

University of Mohammed Premier

Oujda Morocco
J. Mater. Environ. Sci., 2017, Volume 8, Issue 12, Page 4434-4443

http://www.jmaterenvironsci.com /

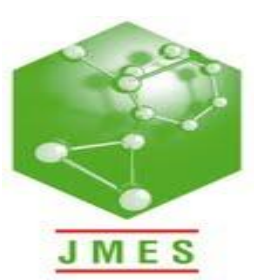

\title{
Study of the colonization of benthic macro invertebrate of Sidi Moussa lagoon (Atlantic Coast-Morocco): Use of an artificial device
}

\author{
R. Massar ${ }^{1}$, A. Essedaoui ${ }^{1,2}$, A. Ferssiwi ${ }^{1}$, A. Aouji ${ }^{1}$, A. Bitar ${ }^{1}$ \\ ${ }^{I}$ Unity of Nutritional Physiopathology and Toxicology - Laboratory BNVRN Faculty of Science of El Jadida, Morocco. \\ ${ }^{2}$ Laboratory of life and earth sciences, Regional Center of the Trades of Education and Training Casablanca - Settat, Section of \\ El Jadida, Morocco.
}



Received 25 May 2017,

Revised 07 Aug 2017,

Accepted 13 Aug 2017

Bitar.a@ucd.ac.ma

Phone: +212661137540

Fax: +212523342187

\begin{abstract}
The aim of this study is to assess the dynamics of colonization and patterns on succession of intertidal macrobenthic fauna living in the Sidi-Moussa lagoon (Atlantic Coast Morocco) using an artificial substrate. To do this, an experimental collector was installed in the median part of the lagoon for eight months. It is comprised of seven shelves. Inside each of it placed; four plates in baked clay numbered (by group of two). Eight plates were collected monthly: four plates having stayed a month in the lagoon and four other cumulative plates who stayed more than a month. These plates are replaced to keep on the field the same number of plate in the crate. The different technical methods, statistics and mathematics used in Ecology (Specific Richness, Shannon index, Evenness) indicate that this colonization may be divided into two periods. A first period of colonization active where the number of colonizing species fluctuate quickly from one month to another and also one levy to the other; a second period, about 4 months after the beginning of the experiment, where the observed variations are lower amplitude. The results reveal a taxonomic diversity of 24 taxa divided into 18 families. For the monthly plates, we counted only the sedentary polychaetes (spirorbis and spirobranchus) with an increasing number in terms of individuals. However, cumulative plaques show a very high rate of fixation of polychaete (spirorbis), which is accompanied by moderately low colonization for gastropods, bivalves, followed by crustaceans and other marine invertebrates (Platyhelminthes, Cnidarians and Echinoderms).
\end{abstract}

\section{Introduction}

Coastal zones are spaces of transition between the earth and the sea; the coastal lagoons brackish are part of coastal ecosystems that receive large quantities of organic nutrients and minerals due to the increase of the anthropogenic activity along these coasts and of the use of agricultural fertilizers in their watershed [1]. These ecosystems are host to a remarkable diversity of species. Crustaceans, polychaetes, bivalves and gastropods are the most typical taxa [2]. The macro-invertebrates represent a relevant component of marine ecosystems and constitute a key element in the benthic communities in lagoon and estuarine areas by supporting their biogeochemical cycles [3].

Coastal development inherent in economic progress has resulted in significant disruptions, particularly to biodiversity, due to their tourism and recreational importance [4]. In addition to climate change, anthropogenic activities threaten the maintenance of the environmental functions and services provided by these coastal ecosystems. These natural disturbances and anthropogenic can induce a recolonization continues in the benthic habitats view coastal that benthic organisms living in shallow waters are very sensitive to a number of disturbances, mainly pollution by the household and industrial waste [5]. Due to the habits relatively sedentary and therefore of the inability to prevent unfavorable conditions, benthic organisms are sensitive indicators to changes in environmental factors [6]. However, the profiles of recolonization may be strongly influenced by the 
quality of the sediments [7]. The rates of recolonization after the disturbance of the ecosystem depend strongly on the type, frequency and intensity of the disturbance, the availability of the larvae, the composition of species, reproductive cycles and strategies of life [8-9].

The use of artificial substrates for the study of benthic macro-invertebrates is common. This method provides information on the growth of algae and to some extent allows quantitative and qualitative observations of material difficult to harvest on natural substrates [10]. Artificial substrates have been used to track benthic communities in several studies [11-14]. They have been proposed to overcome the challenges of recolonization in benthic communities, as they provide standard microhabitats within a spatial scale [13]; Therefore, any difference observed is not attributable to habitat [14]. Wood and concrete are used in coastal ecosystem restoration projects, both of which can provide substrates to be colonized by macro invertebrates [15-16]. In addition, the use of ceramic tiles to study the characteristics and dynamics of recolonization and the biological history traits of marine macro-invertebrates has been widely adopted [17-18].

The Sidi Moussa Lagoon (Moroccan Atlantic Coast) is an invaluable wetland. This ecosystem is exposed to many sources of pollution mainly from anthropogenic and industrial activities [19]. Industrial pollution (proximity to the Jorf Lasfar industrial complex) and organic pollution generated by the lack of sanitation in the surrounding hills, the uncontrolled use of fertilizers, pesticides and plant protection products are among the threats to this area and on its biocenosis [20-21]. This work aims at studying the process of recolonization of the lagoon of Sidi moussa. Indeed, artificial substrates were used to test the modalities of their colonization by benthos invertebrates. We have also tested its compatibility and affinity rate for the fixation of macrobenthic organisms and we have followed the chronology of colonization by invertebrates to know the possibilities of use for a quantitative and qualitative study of lagoon biocenoses.

\section{Material and Methods}

\subsection{Experimental site}

The Sidi Moussa lagoon ( $32^{\circ} 52$ ' 0 ' ' $\mathrm{N} / 8^{\circ} 51^{\prime} 05$ " W) is located on the Moroccan Atlantic coast between the cities of El Jadida and Safi about $15 \mathrm{~km}$ South of the Jorf Lasfar industrial complex (Figure 1). It is located on a rectangle $5.5 \mathrm{~km}$ long by $0.5 \mathrm{~km}$ wide, the total area is estimated at $4.2 \mathrm{~km}^{2}$ [22]. This lagoon is separated from the oceanic domain by a cordon of consolidated dunes ensuring the stability of the lagoon-ocean communication. However, the region is classified in the semi-arid stage, but the lagoon has a Mediterranean climate linked to an oceanic shade [23]. The average annual temperature is about $18.7^{\circ} \mathrm{C}$ and an average annual rainfall of $317 \mathrm{~mm}$. The tidal regime at the lagoon level is of the semi-diurnal type with two full seas and two low seas every 25 hours with a tidal range of between 2 and $4 \mathrm{~m}$ [24].

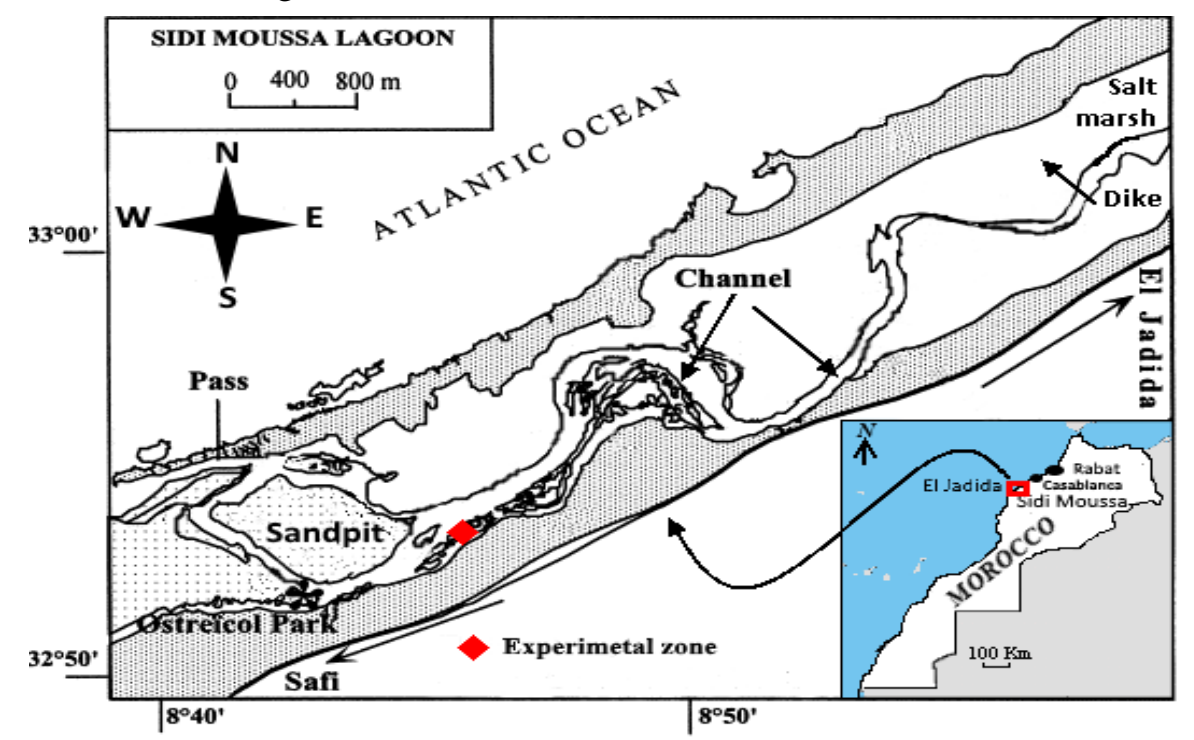

Figure 1: Study area with location of sampling site (Sidi Moussa lagoon- El Jadida Morocco)

\subsection{Artificial device}

An experimental device (artificial collector) was installed in the intertidal zone of the Sidi Moussa lagoon (Figure 1) to demonstrate a timing of fixation and colonization by benthic macroinvertebrates. Follow-up was conducted from March 2016 until October 2016. 
The collector used is a rectangular wooden frame, $1.05 \mathrm{~m}$ long, $40 \mathrm{~cm}$ wide and $18 \mathrm{~cm}$ high (Figure 2). It consists of seven shelves and is subdivided into two lines, each line comprising 14 square plates of clayey nature $15 \mathrm{~cm}$ in length, which are arranged in seven groups of two plates. The distance between the shelves is 15 $\mathrm{cm}$. In addition, the distance between the device and the bottom was $0.5 \mathrm{~m}$. The collector was subjected to a soak period in filtered sea water for one week before immersion in the study area in order to enhance their attractive catchment power. The plates are fixed 2 by 2 to the support by means of a slide, which allows a quick disassembly during the sampling. The whole is immersed with 4 ropes fixed at the collector angles, and connected to the four big stones having the role of supporting the collector of the rocky bottom.

The collector was deposited in March 2016 at the level of the study area, where the environmental conditions and, in particular, the nature of the bottom, the illumination and the hydrodynamism appear substantially homogeneous.
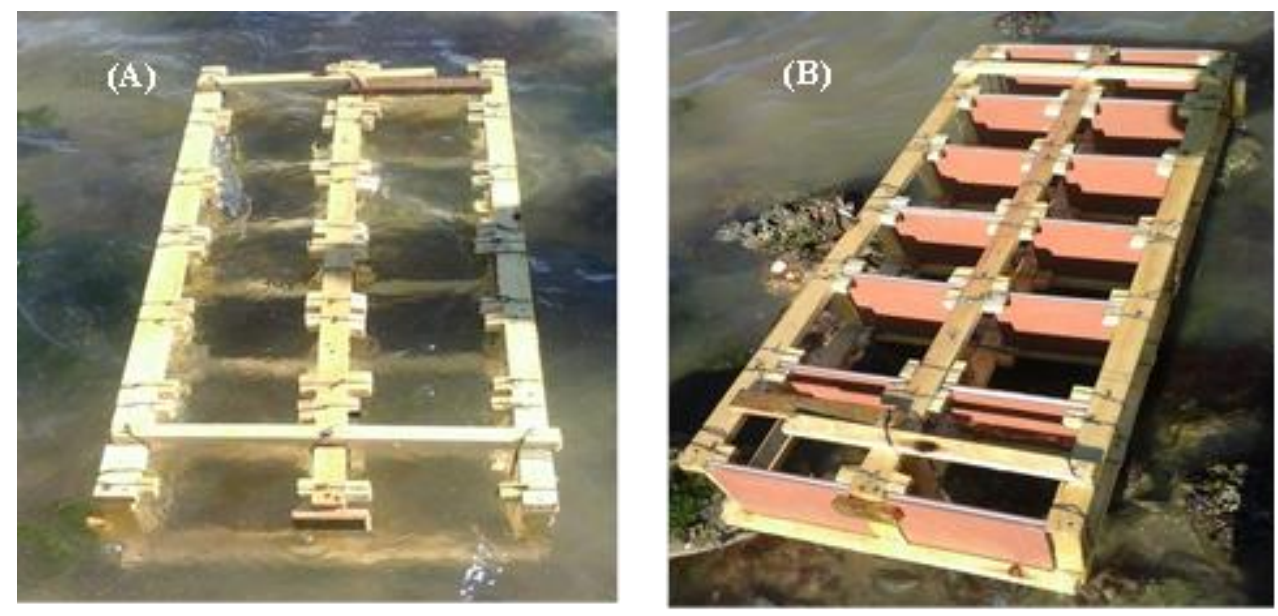

Figure 2 : Photos of the experimental collector supporting the artificial substrate (ceramic plates of clayey nature before (A) and after (B) installation at the lagoon of Sidi Moussa

\subsection{Sampling}

The sampling of the artificial substrates was carried out at low tide after 33, 62, 97, 128, 153, 203 and 218 days of their deposits in the lagoon (Table 1), thus four plates per month (having stayed one month in the Lagoon) and four cumulative patches that have stayed more than one month have been stuck.

Table 1 : Summary table of dates of establishment and survey of substrates.

\begin{tabular}{|c|c|c|c|c|}
\hline $\mathbf{N}^{\circ}$. of visit & $\mathbf{N}^{\circ}$. of Plate & Date of installation & Date of sampling & $\begin{array}{l}\text { Duration of } \\
\text { immersion }\end{array}$ \\
\hline Visit 1 & \multicolumn{4}{|c|}{ Installation of the artificial device on March 22, 2016} \\
\hline Visit 2 & PM1 & 22 March 2016 & 23 April 2016 & 33 Days \\
\hline \multirow{2}{*}{ Visit 3} & PM2 & 23 April 2016 & 21 May 2016 & 29 Days \\
\hline & PC1 & 22 March 2016 & 21 May 2016 & 62 Days \\
\hline \multirow{2}{*}{ Visit 4} & PM3 & 21 May 2016 & 24 June 2016 & 35 Days \\
\hline & PC2 & 22 March & 24 June 2016 & 97 Days \\
\hline \multirow{2}{*}{ Visit 5} & PM4 & 24 June 2016 & 24 July 2016 & 31 Days \\
\hline & PC3 & 22 March & 24 July 2016 & 128 days \\
\hline \multirow{2}{*}{ Visit 6} & PM5 & 24 July 2016 & 17 August 2016 & 25 Days \\
\hline & PC4 & 22 March & 17 August 2016 & 153 days \\
\hline \multirow{2}{*}{ Visit 7} & PM6 & 17 August 2016 & 05 October 2016 & 50 Days \\
\hline & PC5 & 22 March & 05 October 2016 & 203 days \\
\hline \multirow{2}{*}{ Visit 8} & PM7 & 5 October 2016 & 20 October 2016 & 15 Days \\
\hline & PC6 & 22 March & 20 October 2016 & 218 days \\
\hline
\end{tabular}

*PM1, PM7 : monthly plates 1 numbered 1 to 7 ; PC1 to PC6: cumulative plates numbered 1 to 6

In addition, four new plates were installed in place of the removed plates in order to keep the same number of plates in the crate on the ground. The frequency and the recovery dates of the substrates make it possible to determine the duration of the exposure time (Table 1). The removed plates were carefully placed in order, were 
preserved in a $10 \%$ formalin seawater solution. In the laboratory, benthic animals were sorted under a binocular dissecting microscope, identified to the lowest possible taxonomic levels and counted.

The survey of the plates on a monthly basis allowed us to follow the succession and chronology of colonization of the virgin artificial substrate by the benthic invertebrate macros. However, the cumulative records revealed the dynamics of colonization of the species and the evolution of their numbers during the study period in order to determine when this substrate harbors a stable stand.

\subsection{Processing of Data}

Within a biocenosis, the balance of the stand depends not only on the strength of individuals and the number of taxa that it houses, but mainly in the distribution of abundance of staff between the species. In order to establish this aspect we have addressed two important clues:

- Shannon-Wiener's index (H') [25] that informs us about the specific diversity. This index takes into account not only the total number of individuals $(\mathrm{N})$ and the total number of species (S), but also the number of individuals (NI) to the inside of the species (I). It is expressed by the following formula:

$$
\mathbf{H}^{\prime}=-\sum[(\mathbf{N i} / \mathbf{N}) * \mathbf{L N}(\mathbf{n i} / \mathbf{N})] \text {. }
$$

- Pielou's index (J) [26] which we allows to calculate the Eveness. This index is expressed by the following formula:

$$
\mathbf{J}=\mathbf{h}^{\prime} / \mathbf{H m a x} \text {; Where Hmax }=\log 2(\mathrm{~S})
$$

\section{Results}

A total of 24 taxa were collected and identified on the artificial substrate in the course of this study (Table 2), with 6 bivalves, gastropods 6, 4 Polychaetes, 3 Crustaceans, 2 Cnidaria, 2 Polyplacophores and 1 flatworm. On also notes a strong colonization by the green alga Ulva lactica and a few bacterial biofilms. However, the majority of taxa harvested are typical of rocky Fund (hard) Soft. For the monthly plates, a peak of specific recruitment (number of species laid down) is observed during the month of August-16 (approximately 25 days of immersion) and a higher average value of density is recorded in Seven-16 (approximately 50 days of immersion). Moreover, a peak early start is observed during the month of July-16 for the cumulative plates (approximately 128 days in immersion) with an average density higher in August. The Molluscs (gastropods and bivalves) and the Polychaetes sedentary opportunists were the animals most abundant and more frequent on these artificial plates.

\subsection{Evolution of the number of species and the number of individuals \\ * The monthly plates: plates that have stayed only one month in immersion in the lagoon}

The number of taxa on these plates gradually increases during the first four months of immersion (April, May, June and July) and then stabilizes between 5 and 7 taxa in August (Figure 3).

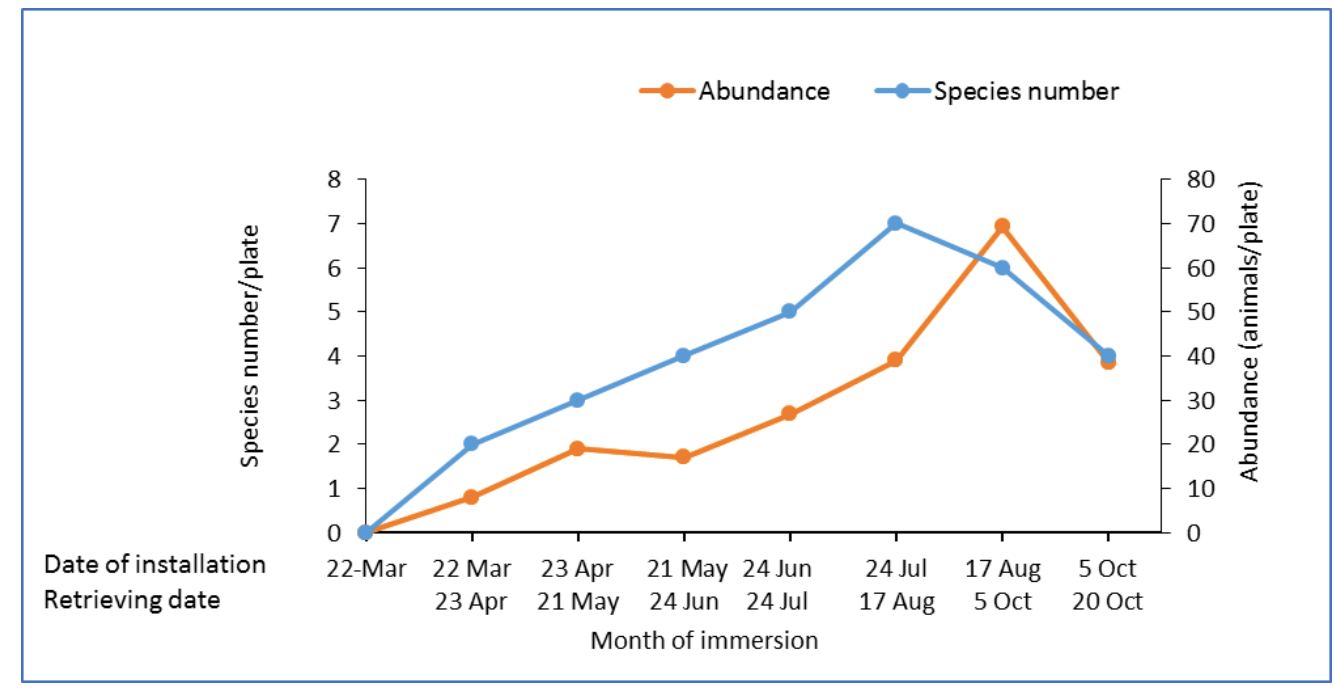

Figure 3: Evolution of the number of species and individuals in function of months of immersion (monthly plates) 
Table 2: List and number of species harvested on each substrate during the study period.

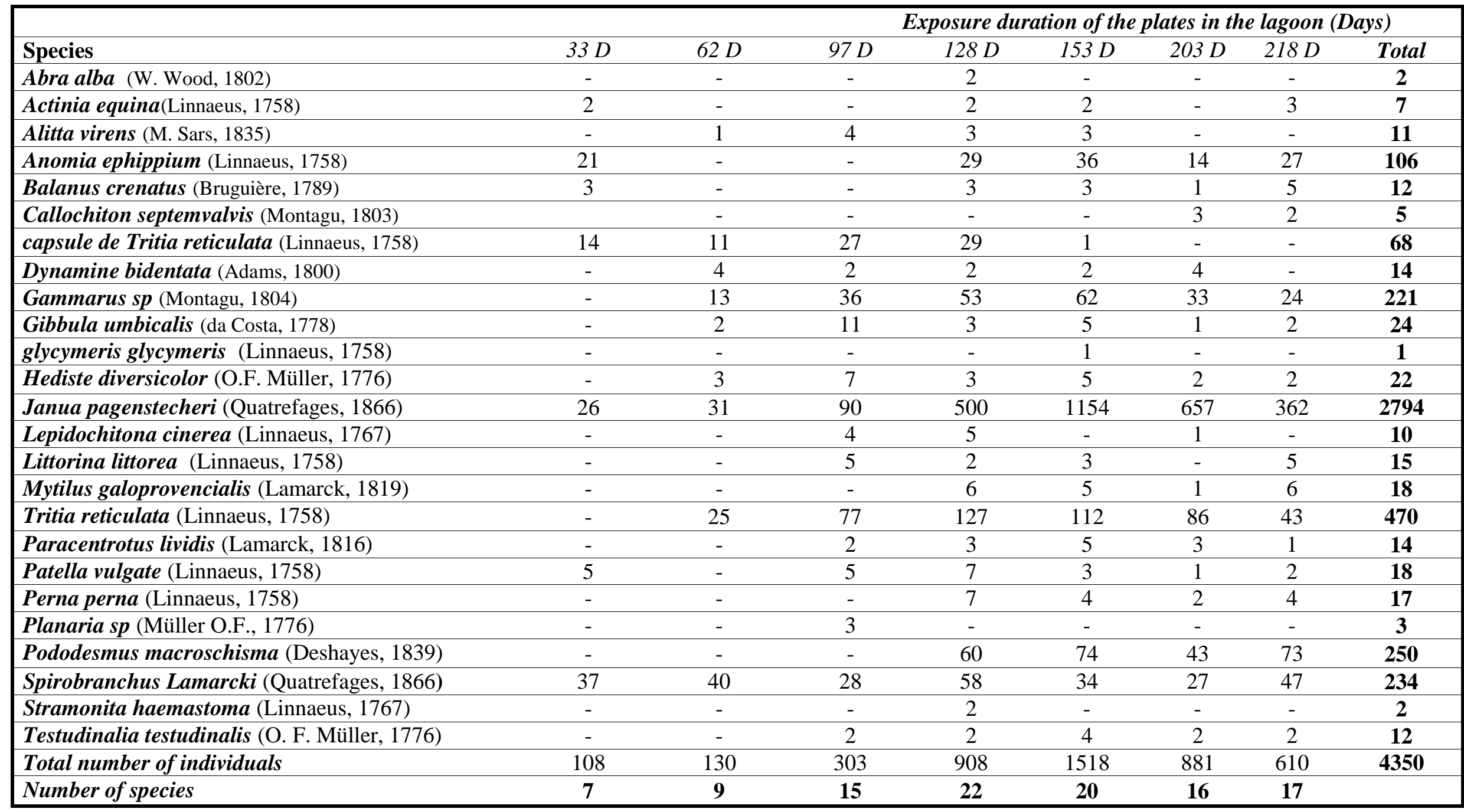


In April and May, three taxa appeared on the plates (Janua pagenstecheri, Spirobranchus Lamarcki and some larval capsules of Tritia reticulata) with an average of 8 individuals per plate. During this period, colonization appears to be weakly restricted and largely (about 97\%) assured by sedentary polychaetes (spirorbis, spirobranchus) (Figure 4). During the months of June, July and August, 5 new taxa appeared on the plates (Patella vulgata, Balanus crenatus, Anomia ephippium, Pododesmus macroschisma, Actinia equina) whereas the number of individuals reached a maximum value during these months of exposure including September with a slight decrease in October.

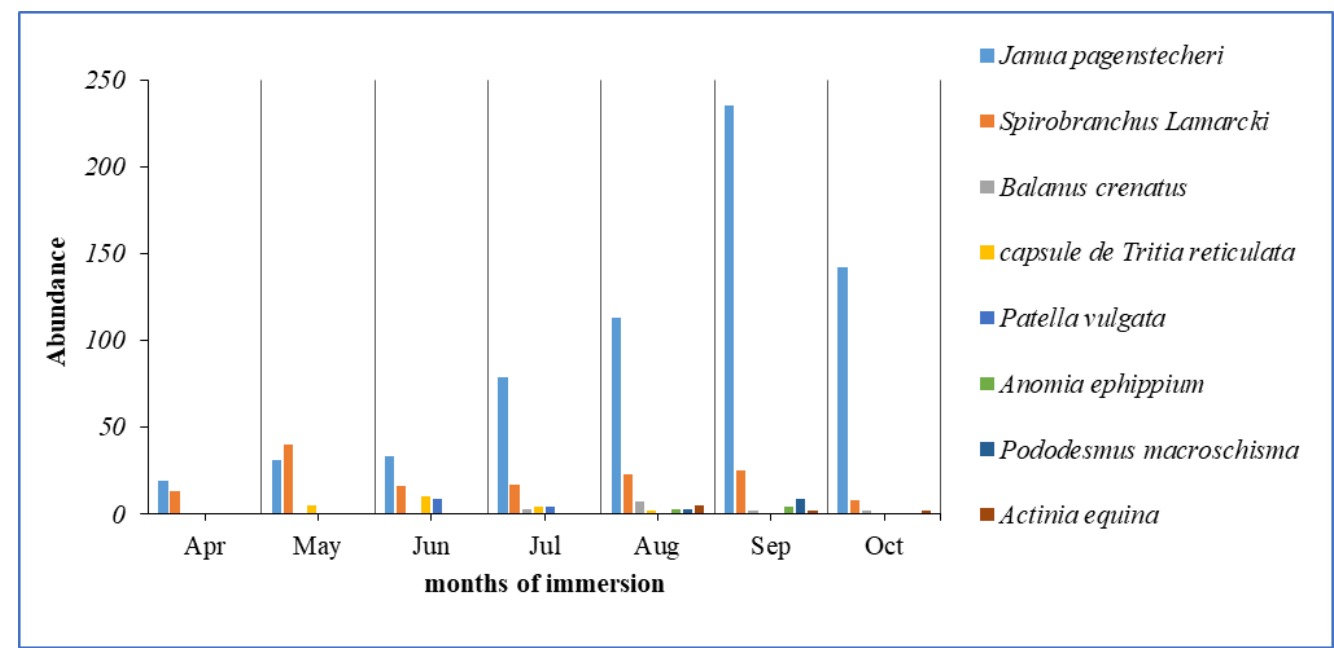

Figure 4: Abundance of individuals colonizing the plates by months of immersion (monthly plates)

* Cumulative plates : plates that have stayed more than one month in immersion in the lagoon

After 62 days of exposure, 9 species appeared on artificial plates with 130 individuals, including the presence of reticulated net larvae and sedentary polychaetes forming sinuous limestone tubes. For 97 days, the plates host 15 species and an average of 303 individuals of which $29.7 \%$ of spirorbis and $35 \%$ of reticulated net $10 \%$ of them are young larvae. After 128 days, the plates fixed 22 species and 908 individuals, with a remarkable predominance of sedentary polychaetes $184 \%$. Polychaete numbers continued to increase until 153 days of immersion and subsequently decreased considerably (Figure 5). For the others, macro-invertebrates, a month-tomonth fluctuation is observed. However, some species colonized this substrate only accidentally or temporarily in the young stage of their development (glycymeris glycymeris, Stramonita haemastoma, Planaria sp, Actinia equina Lepidochitona cinerea, Callochiton septemvalvis, Stramonita haemastoma).

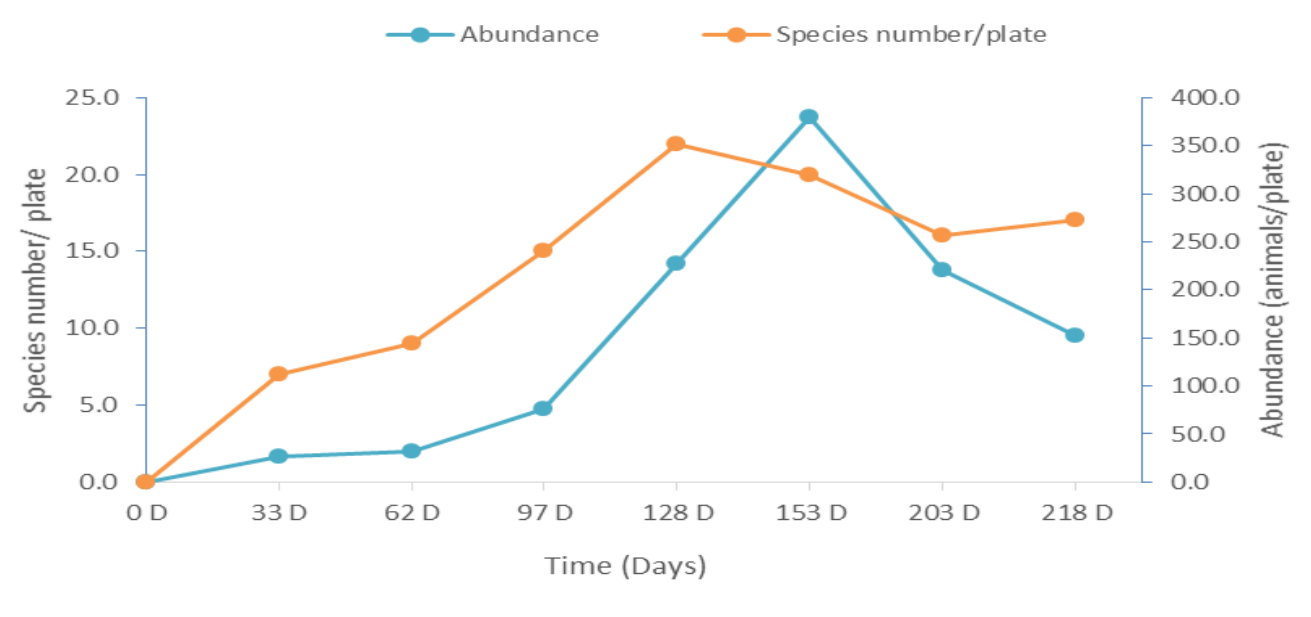

Figure 5: Evolution of the number of species and individuals according to months of immersion (cumulative plates)

The number of taxa fixed on the plates grows strongly during the first four months of exposure and then stabilizes between 5 and 6 species for the monthly plates and between 16 and 20 for the cumulative plaques. In fact, the density of individuals is strongly correlated with the specific richness during these first months of 
immersion (Figure 5). First, strong colonization is observed by the dominant taxa: sedentary polychaetes (Serpulidae). The period of exposure followed by the gastropods but the growth of the bivalve numbers (Anomiidae) is only important between August and October, as well as the presence of certain mobile taxa (Gammaridae and Nassariidae) (Figure 6).

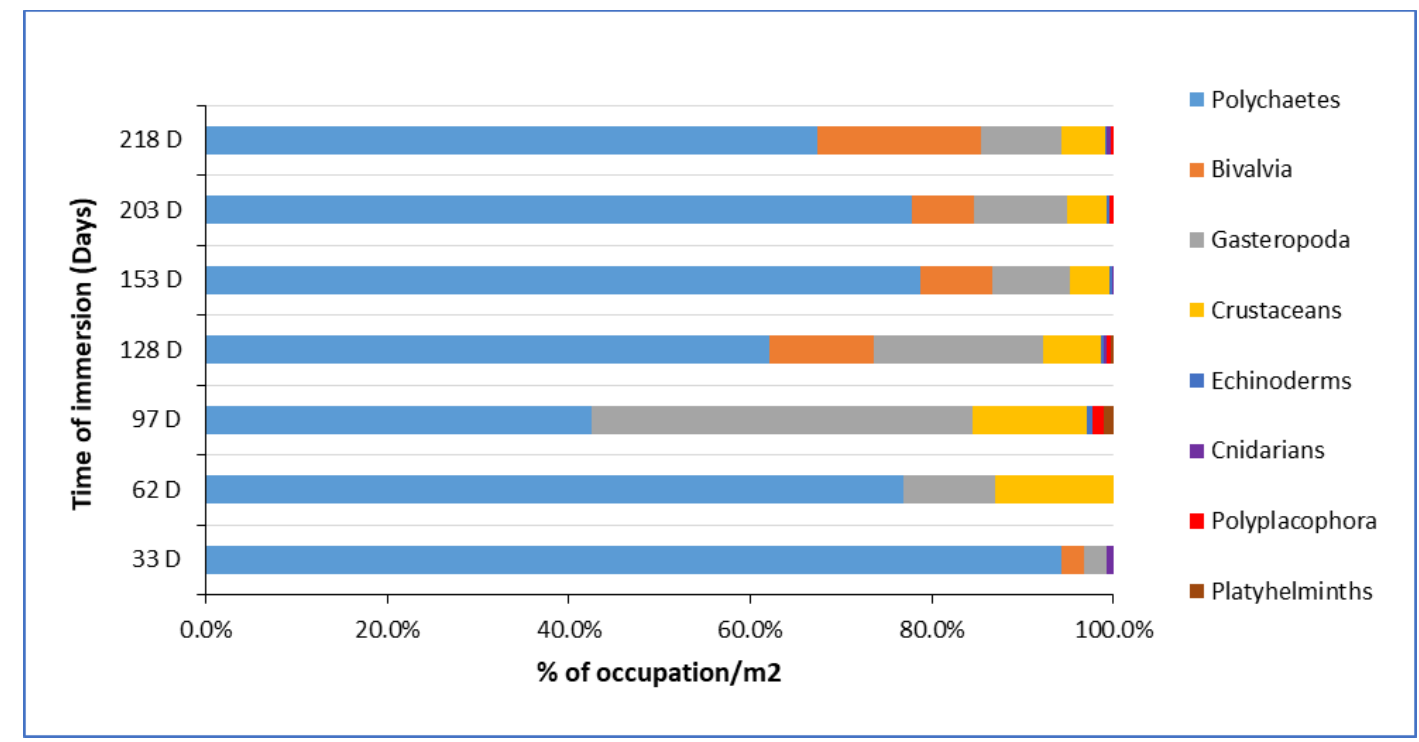

Figure 6: Percentage of individuals by zoological group as a function of immersion time

The equilibrium within this micro-biocenosis depends not only on its numbers and the number of taxa that it contains, but also on the distribution of abundance of numbers between the species. This aspect is addressed by drawing on the calculation of specific diversity and Evenness (Figure 7). Specific diversity (H ') and Evenness (J) showed a similar trend during the study period. Both indices increased to a peak ( 2.88 for $\mathrm{H}$ 'and 0.75 for $\mathrm{J})$ after three months, then declined slowly to a low level (1.16 for $\mathrm{H}^{\prime}$ and 0.29 for $\mathrm{J}$ ) in September.

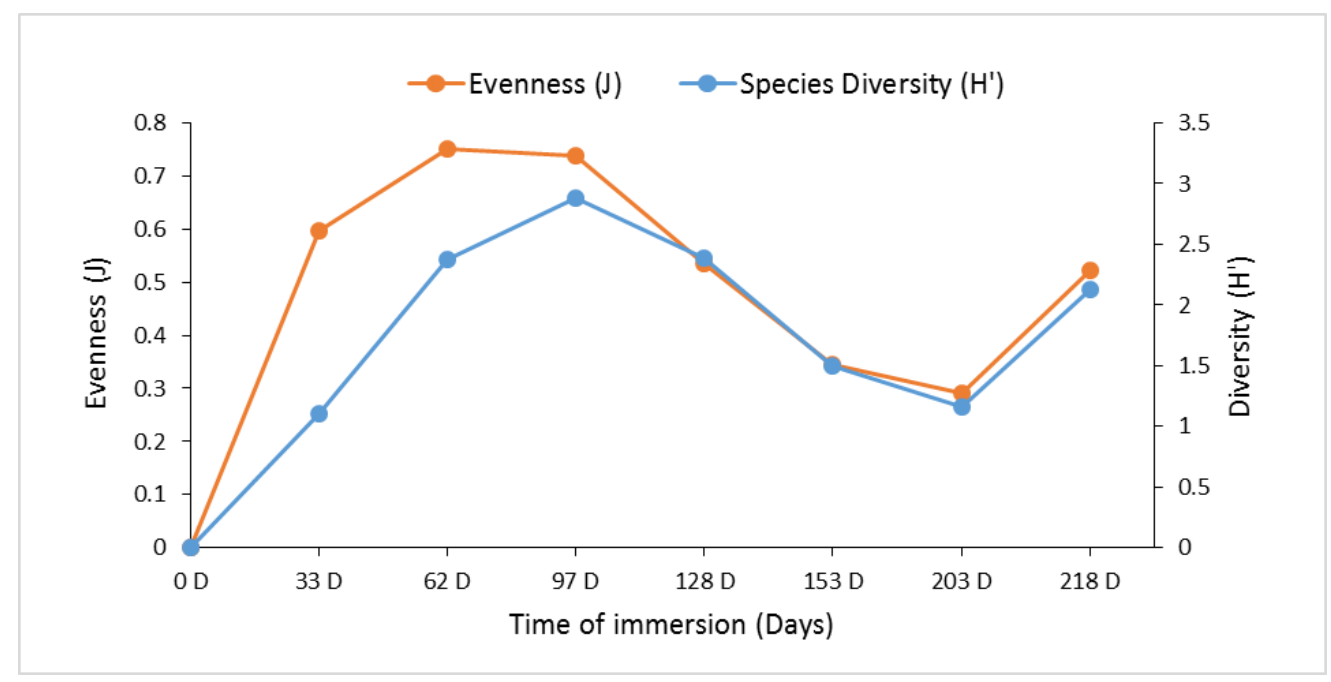

Figure 7: Evolution of the values of Species Diversity and Evenness as a function of immersion time

\section{Discussion}

During the study period from March-16 to October-16, we identified 24 macrobenthic species with more dominant polychaetes, followed by molluscs (bivalves and gastropods) and crustaceans (Figure 6). This number is lower than that observed by $\mathrm{Lu}$ (2006) [27] and Wang (2013) [28]. These first results seem to show the existence of a stabilization of the number of taxa from the 4th month of exposure. However, it is not until the 
5th month that the number of individuals reaches its optimum and then decreases during the last months of the experiment.

Colonization of the artificial substrate (ceramic plates of clayey nature) is mainly provided by fixative forms, free and mobile, with a varied diet: primary consumers; Detritivores; predators. This process was initiated by sedentary polychaetes, this finding is confirmed by several authors [27-28]. This colonization appears to be restricted, mainly by polychaete (Serpulidae), bivalves (Anomiidae) and Gasteropods (Nassaridae and Patellidae). According to Kevin et al. (2009) [29], the period of exposure of substrates in the Waikato River in New Zealand is two months to have a similar fauna to the substrate. While for our study at the Sidi Moussa lagoon, it takes about 3 to 4 months of immersion to obtain on the substrates a fauna comparable to that of the surrounding biotope. This time appeared longer and can be attributed to the fact that the plates are initially devoid of nutritional algal cover. In addition, the lengthening of colonization time by benthic macroinvertebrates may correspond to the time required for proper colonization by algae and organic particles used as nutrients for macrobenthic larvae.

However, temporal changes in macrofauna are largely related to seasonal variations in species breeding activities [30-31]. During the first 4 months of this study, we observed that pioneer species have a very high colonization rate (Serpulidae and Anomiidae), which implies a strong dispersal of larvae with rapid growth during late spring and summer. Opportunistic species such as sedentary polychaetes (Janua pagenstecheri, Spirobranchus Lamarcki) often have low competitiveness and are generally replaced by other species later on after sediment preparation, making it more suitable for other species Install [32]. In this study, the dominance of Janua pagenstecheri ended after a severe fall and substitution by bivalves, eg Anomia ephippium and Pododesmus macroschisma. The abrupt decline in the population of certain species (Janua pagenstecheri) may result from interspecific competition, intraspecific depletion of food resources or accumulation of toxic substances [27]. On the other hand, certain taxonomic groups of this biocenosis colonized this substrate only accidentally or temporarily at the young stage of their development (Anthozoa, Echinoderms, Polyplacophores and Malacostraces).

Anomia ephippium and Pododesmus macroschisma were the main colonizers of ceramic tiles from August to Nov-16 after Janua pagenstecheri later they were submerged by other species. The anomie species (Anomia ephippium) is rare in surrounding natural assemblages, but its planctotrophic larva has a long dispersal capacity and several breeding events occur during the year [33]

The present study also shows that an immersion time of at least 4 months is necessary to have a decrease in the variability of certain parameters (Density, Diversity, Evenness) indicating the acquisition of a certain state of equilibrium. However, this duration is likely to vary under the combined influence of various factors such as the nature and type of stream stand, the season and the type of artificial substrate used [34]. However, severe changes in hydrodynamic conditions may affect larval dispersal and recruitment [35].

The intensive use of pesticides and fertilizers in the adjacent arable land of the Sidi Moussa lagoon (Morocco) favors the massive proliferation of algal species that will contribute to the eutrophication of the environment. Shallow lagoons tend to be dominated by macroalgae and benthic microalgae rather than phytoplankton. However, moderate nutrient intakes generally lead to an increase in primary production by contributing to overall environmental productivity growth [36]. Many authors have demonstrated the importance of benthic macrophytes in nutrient cycles in lagoon ecosystems [37-38], eutrophication. Durig the final phase of eutrophication, there is usually a higher density of phytoplankton and / or a floating biomass of macroalgae with limited benthic production due to shading and even dystrophic events may occur: Oxygen depletion at the bottom, release of toxic hydrogen sulphide and mass mortality of zoobenthos [35].

Our results support the idea that summer temperature is an important factor in the distribution and variability of benthic macrofauna in the Sidi Moussa lagoon. Several authors Wieking and Kröncke (2001) [35] have shown that in many cases the distribution of species followed specific summer isotherms. These observations contrast with several studies in the Wadden Sea and coastal areas, which indicate that cold winters are important determinants of changes in macrobenthic communities [39]. These communities are strongly affected by cold temperatures, indicating that winter has not favored the survival of dominant species. According to Buchanan and Moore (1986) [40], cold winters favored the survival of dominant species in a sublittoral benthic station off Northumberland, and those at the expense of lesser species due to reduced primary production, resulting in low diversity.

The coastline of El Jadida (Morocco) is more windy during the winter, during the wet period (from November to April), the dominant winds come from the N, NE and NW sectors. These cold winds come in contact with 
winds of ocean origin (SW and $\mathrm{W}$ ) bringing the rains. In addition to their influence on the morpho-sedimentary dynamics, these winds have a constraining effect on the growth of relatively low-density vegetation over the entire coastal extension (Maanan, 2003) [22]. This can affect the specific diversity of the environment. In our opinion, it is probable that our results are mainly related to an increase in the North wind stress or the height of the waves.

Based on our results, the density of polychaeta Janua pagenstecheri was extremely high in this area as well as the density of Anomia ephippium, Pododesmus macroschisma and gastropod Tritia reticulata. The presence of mature adults, such as gastropods Tritia reticulata and Littorina littorea, was noted in the plates collected during the sampling months, indicating that in addition to larval Less some of the mobile adult fauna in or out of the plates has been possible. This confirms that the recolonization process in a lagoon environment was highly dependent on the migration of adults in the sediments adjacent to the experimental collector.

\section{Conclusion}

In conclusion, the colonization processes observed on virgin artificial substrates deposited directly on natural substrates is in agreement with the spatial competition strategies of solitary and colonial species. Indeed, as observed in many rocky habitats throughout the world, colonization was primarily initiated by pioneer species such as sedentary polychaetes and bivalves, while colonial animals and algae can overcome them later.

This study helped to make a specific inventory of the benthic invertebrate macro in the Sidi Moussa lagoon and to advance our understanding of the succession of benthic colonization in this ecosystem. The assessment of the impacts of anthropogenic and natural factors is still under way to further elucidate this process, to maintain and properly manage the biodiversity of a lagoon ecosystem on the Moroccan coasts. These datasets may also be useful for interpreting long-term changes in relation to other stressors (eg, climate change or human activities).

Further knowledge of the biology and distribution of many species is still insufficient for the study area. Indeed, the exploration of the mechanisms of colonization of artificial substrates opens interesting prospects for biomonitoring programs, indicating that artificial substrates could also be used to monitor the evolution of in situ biological diversity related to the different sources of pollution, Anthropogenic origin by implementing appropriate conservation strategies. Finally, the provision of this information could be valuable for future comparisons to predict future changes in the distribution and abundance of benthic assemblages.

\section{References}

1. Javier L., Arnaldo M., Marin. Pollut. Bull. 58 (2009) 1827-1834

2. Rodil I.F., Lastra. M., Estuar. Coast. Shelf. S. 61 (2004) 37- 44.

3. Levin L., Etter R. ., Rex M.A., Gooday A.J., Smith C.R., Pineda J., Stuart C.T., Hessler R.R., Pawson D., Annu. Rev. Ecol. Evol. Syst. 32 (2001) 51-93.

4. McLachlan A., Defeo O., Jaramillo E., Short A.D., Ocean. Coast. Manag. 71 (2013) 256-268.

5. Negrello-Filho O.A., Underwood, A.J., Chapman, M.G., J. Exp. Mar. Biol. Ecol. 328 (2006) 240-250.

6. Susana C., Perez-Ruzafa A., Gamito S., Estuar. Coast. Shelf. S. 167 (2015) 276 - 285.

7. Fabiana R.G., Paulo C.L., Mar. Pollut. Bull. 67 (2013) 107-120.

8. Lu L., R.S.S. Wu R.S.S., Mar. Pollut. Bull. 54 (2007) 195-205.

9. Silvana N.R., Birchenough N., Chris L.J., Frid L., J. Sea. Res. 62 (2009) 258-267.

10. Laville H., Annls. Limnol. 10 (2) (1972) 163-172.

11. Russel B.D., Gillanders B.M., Connell S.D., Mar. Ecol. Prog. Ser. 296 (2005) 31-38.

12. Rule M.J., Smith S.D.A., J. Exp. Mar. Biol. Ecol. 345 (2007) 38-51.

13. Mirto S., Danovaro R., Mar. Pollut. Bull., 48, (2004) 919-926.

14. Chapman M.G., Underwood A.J., Mar. Ecol. Prog. Ser. 354 (2008) 147-160.

15. Tullos D.D., Penrose D.L., Jennings G.D., Ecol. Eng. 27 (2006) 228-241.

16. Nneka D., Molokwu P.G., Vaz T.B., Bradshaw T., Blake B., Henessey C., Merten E., Ecol. Eng. 73 (2014) 109-114.

17. Mundy, C.N., Coral. Reefs. 19 (2000) 124-131.

18. English S., Wilkinson C., Baker V., Survey Manual for Tropical Marine Resources. 2nd edition. Australian Institute of Marine Sciences, Townsville, Austria (1997).

19. Joulami L., Daief Z., Elmalki S., El Hamoumi R., ScienceLib. Ed. Vol 5 N 130702 (2013).

20. Essedaoui A., Kerambrun P., Alliot E., Sif J., Mar. Life. 11 1-2 (2001) 21-31. 
21. Maanan M., Zourarah B., Carruesco C., Aajjane A., Naud J., Afr. Earth. Sci. 39 (2004) 473-483.

22. Maanan M., Etudes sédimentologique du remplissage de la lagune de Sidi Moussa (Côte Atlantique Marocaine). Thèse de doctorat en Géologie, Université Chouïab Doukkali, (2003) 164pp.

23. Atillah A., Etud. Médit. 16 (1994) 73-95.

24. Hilmi K., Orbi A., Lakhdar J., Sarf F., Chagdali M., Actes Colloques Hydrodynamique Marin 02, Faculté des sciences de Ben M'Sik, Casablanca, Tome I, (2002) 1-6.

25. Shannon C.E., Weaver W., The Mathematical Theory of Communication. University of Illinois Press, Urbana, Illinois, (1963) 125 pp.

26. Pielou E.C., Am. Nat. 100 (1966) 463-465.

27. Lu L., Wu R.S.S., Estuar. Coast. Shelf. S. 68 (2006) 627-634.

28. Wang Q., Han Q., Lil B., Biodivers. Sci. 21 (1) (2013) 11-18.

29. Kevin J., Collier M., Hamer W., Lindsay C., New. Zeal.Nat. Sci. 34, (2009) 49-61.

30. Veloso V.G., Cardoso R.S., Fonseca D.B., Oecologia brasiliensis 3 (1997) 213-225.

31. Neves L.P., Silva P.S.R., Bemvenuti C.E., Iheringia 98 (1), (2008) 36-44.

32. Fava F., Ponti M., Abbiati M., PLoS ONE 11(10) (2016) : e0163494. doi:10.1371.

33. Bramanti L., Magagnini G., Santangelo G., Ital. J. Zool. 70 (2003) 175-178. doi: 10.1080.

34. Khalaf G., Tachet H., An. Limnol. 13 ( 2) (1977) 169-190.

35. Wieking G.K.G., Krönke I., Senckenbergiana marit. 31 (2) (2001) 125-141.

36. Gray J.S., Eutrophication in the sea. In: Colombo, G., Ferrari, I., Ceccherelli, V.U., Rossi, R. (Eds.), Marine Eutrophication and Population Dynamics. Olsen and Olsen, Fredensborg, Denmark, (1992) pp. $3-15$.

37. Fong P., Zedler J.B., Donohoe R.M., Limnol.Oceanogr. 38 (1993) 906-923.

38. Viaroli P., Bartoli M., Bondavalli C., Christian R.R., Giordan G., Naldi M., Hidrobiol. 329, (1996) 105119.

39. Beukema J.J., Essink K., Michaelis H., ICES J.Mar. Sci. 53 (1996) 964-971.

40. Buchanan J.B., Moore J. J., Hydrobiol. 142 (1986) 121-127. 